\title{
Correction to: Design and development of Slotted Stack-Petal Pot (SSPP) chimney and its performance analysis over conventional chimney
}

\author{
P. Priyadharshini ${ }^{1}$ - S. Karthikeyan ${ }^{1}$
}

Published online: 14 May 2020

(c) Islamic Azad University (IAU) 2020

\author{
Correction to: \\ International Journal of Environmental Science and \\ Technology \\ https://doi.org/10.1007/s13762-020-02712-1
}

The article listed above was initially published with author father's name instead of author names.

Author names are corrected in original article.

The original article can be found online at https://doi.org/10.1007/ s13762-020-02712-1.

P. Priyadharshini

priya05civilian@gmail.com

1 Centre for Environmental Studies, College of Engineering, Guindy, Anna University, Chennai, Tamilnadu, India 